\title{
Identification of Two Novel Missense Mutations (p.R1221C and p.R1357W) in the ABCC6 (MRP6) Gene in a Japanese Patient with Pseudoxanthoma Elasticum (PXE)
}

\author{
Yoshihiro NoJI, Akihiro InAzU, Toshinori HigashiKata, Atsushi NoHARA, \\ Masa-aki KAWASHIRI, Wenxin YU, Yasuhiro Todo, Tsuyoshi NOZUE, \\ Yoshihide UNO*, Senshu HIFUMI** and Hiroshi MABUCHI
}

\begin{abstract}
Pseudoxanthoma elasticum (PXE) is a rare, inherited, systemic disease of elastic tissue that in particular affects the skin, eyes, and cardiovascular system. Recently, the ABCC6 (MRPG) gene was found to cause PXE. A defective type of $A B C C 6$ gene (16p13.1) was determined in two Japanese patients with PXE. In order to determine whether these patients have a defect in $A B C C 6$ gene, we examined each of 31 exons and flanking intron sequences by PCR methods (SSCP screening and direct sequencing). We found two novel missense variants in exon 26 and 29 in a compound heterozygous state in the first patient. One is a missense mutation (c.3661C $>T$; p.R1221C) in exon 26 and the other is a missense mutation (c.4069C $>\mathrm{T}$; p.R1357W) in exon 29. These mutations have not been detected in our control panel of 200 alleles. To our knowledge, this is the first report of mutation identification in the $A B C C 6$ gene in Japanese PXE patients. The second patient was homozygous for 2542_2543delG in ABCC6 gene and heterozygous for 6 kb deletion of $L D L-R$ gene. This case is the first report of a genetically confirmed case of double mutations both in PXE and FH loci.
\end{abstract}

(Internal Medicine 43: 1171-1176, 2004)

Key words: pseudoxanthoma elasticum, PXE, ATP binding cassette transporter, ABCC6, MRP6, membrane transporter proteins, calcification

\section{Introduction}

Pseudoxanthoma elasticum (PXE [OMIM 177850 and OMIM 264800]) is a heritable disorder of the connective tissue characterized by progressive calcification of elastic fibers in skin, retina, and the cardiovascular system. PXE is usually inherited as an autosomal recessive trait, but examples of autosomal dominant and sporadic forms of PXE have been reported. The prevalence of the disease in the general population ranges between 1/70,000 and 1/160,000 (1).

Recently, mutations in the ABCC6 (MRP6) gene have been identified to be responsible for PXE $(2,3)$. The precise function of ABCC6 is currently unknown. The ABCC6 gene is predominantly expressed in both the liver and kidney (4), although these two organs were not thought to be involved in the development of PXE.

Le Saux et al demonstrated that the nonsense mutation p.R1141X and a large deletion spanning from exon 23 to exon 29 were relatively common mutations in a cohort of 122 patients from the United Kingdom, the United States, South Africa, Italy, Germany, and Belgium (5). However with the exception of one case report (6), to date there have been no studies that analyzed mutations in the ABCC6 gene in PXE patients of Asian origin.

Here, we describe two unrelated Japanese patients affected by PXE and their family members. We provide the result of our mutational analysis of the $A B C C 6$ gene and discuss the significance of the mutations identified.

\footnotetext{
From the Molecular Genetics of Cardiovascular Disorders, Division of Cardiovascular Medicine (The Second Department of Internal Medicine), Graduate School of Medical Science, Kanazawa University, Kanazawa and *the Department of Cardiology, Ishikawa Prefectural Central Hospital, Kanazawa and **the Department of Internal Medicine, Hokuriku Central Hospital, Oyabe

Received for publication March 3, 2004; Accepted for publication August 28, 2004

Reprint requests should be addressed to Dr. Yoshihiro Noji, the Molecular Genetics of Cardiovascular Disorders, Division of Cardiovascular Medicine, Graduate School of Medical Science, Kanazawa University, 13-1 Takara-machi, Kanazawa 920-8641
} 


\section{Patients and methods}

\section{Case presentations}

Case 1

Case 1 was a 23 -year-old female, with yellow-colored skin lesions since her early teens. She experienced shortness of breath during the previous two years. She was diagnosed with PXE by skin biopsy with Elastica van Gieson staining and presented opthalmological manifestations. Cardiac catheterization revealed coronary stenosis; two $90 \%$ stenoses were present in the right coronary artery (RCA), the left circumflex coronary artery (LCX) had a 95\% stenosis (Fig. 1A). There was no family history of PXE and her parents marriage was not consanguineous (Fig. 2).

\section{Case 2}

Case 2 was a 75-year-old female. She was clinically diagnosed with PXE associated with familial hypercholesterolemia (FH), and reported by us (7) at the age of 53. She was hypertensive $(210 / 110 \mathrm{mmHg}$ ) and had a history of cerebral bleeding resulting in right hemiparesis at the age of 55 . Yellow-colored skin lesions were observed on her neck, axilla, umbilical and inguinal regions. Umbilical skin biopsy revealed characteristic fragmentation, clumping and calcification of elastic tissue by Elastica van Gieson and Kossa stain. She did not have any ophthalmological manifestation. Laboratory data showed TC of $7.88 \mathrm{mmol} / l(305 \mathrm{mg} / \mathrm{dl})$, TG of $1.57 \mathrm{mmol} / \mathrm{l}(139 \mathrm{mg} / \mathrm{dl})$ and HDL-C of $0.80 \mathrm{mmol} / \mathrm{l}(31$ $\mathrm{mg} / \mathrm{dl}$ ). Achilles tendon thickness by X-ray examination was $16 \mathrm{~mm}$ (normal thickness $<9 \mathrm{~mm}$ ). Her second son also had hypercholesterolemia (TC: $8.84 \mathrm{mmol} / l ; 342 \mathrm{mg} / \mathrm{dl}$ ) and Achilles tendon xanthoma. The electrocardiogram (ECG) of this proband showed horizontal ST segment depression in I, II, ${ }_{\mathrm{a}} \mathrm{V}_{\mathrm{L}}, \mathrm{V}_{3-6}$ leads. Remarkable calcification was apparent from the ascending aorta to the femoral arteries as well as the coronary arteries by X-ray examination and computed tomography (Fig. 1B, C). Her father, elder brother and the third son died from heart disease at 58, 53 and 22 years old, respectively. The proband and proband's second son had hypercholesterolemia, although the other members did not. There was no family history of PXE (Fig. 2).

\section{Mutation detection}

Written informed consent was obtained from all participants. The Institutional Review Board of each institution had approved this study. Blood samples were collected from the patients and 100 unaffected and unrelated Japanese control individuals. Genomic DNA was isolated from peripheral blood leukocytes according to standard procedures and was used as a template for polymerase chain reaction (PCR). The sequence information was obtained from the published sequence of human chromosome 16 BAC clone A-962B4 (GenBank Accession No. U91318) and the intron-exon borders for the 31 exons in $A B C C 6$ were inferred by comparison with the published cDNA sequence (GenBank Accession
No. AF076622, the primer sequences are available in Table 1). PCR products were $142-368 \mathrm{bp}$ and included complete intron/exon boundaries and were screened by SSCP (singlestrand conformation polymorphism) analysis (8). Sequence analysis was carried out with the dideoxynucleotide chain termination method, using a Thermo sequenase II (Amersham Pharmatica Biotech, Cleveland, OH, USA) in ABI 310 automated DNA sequencer (PerkinElmer, Foster City, CA, USA). The mutations found in the ABCC6 gene were further confirmed by the PCR-restriction fragment length polymorphism (RFLP) method.

\section{Screening for the deletion ABCC6del23-29}

We screened for the $16.5-\mathrm{kb}$ Alu-mediated deletion (ABCC6del23-29) that extends from intron 22 to intron 29 and that has been reported to be a relatively common in Caucasian PXE patients using the method previously described (9)

\section{Results}

Two novel mutations of the $A B C C 6$ gene were identified in case 1. One was a heterozygous missense mutation (c.3661C>T; p.R1221C) in exon 26 and the other was a heterozygous missense mutation (c.4096C $>\mathrm{T} ; \mathrm{p} . \mathrm{R} 1357 \mathrm{~W}$ ) in exon 29 of the $A B C C 6$ gene. The c.3661C $>\mathrm{T}$ mutation predicted the creation of a novel recognition site for $T s p E$ I and the loss of a Taq I restriction site. The variant c. $4096 \mathrm{C}>\mathrm{T}$ in exon 29 results in the gain of a novel Mae II restriction endonuclease recognition site and in the loss of a Acc II restriction endonuclease recognition site.

Case 2 was homozygous for the deletion 2542_2543delG in exon 19 of $A B C C 6$ and heterozygous for a $6 \mathrm{~kb}$ deletion (FH-Tonami-1) in the LDL receptor gene (10). This is the first reported case of the molecular diagnosis of mutations in both the PXE locus and the FH locus in a patient affected with both diseases. The second son of case 2 was heterozygous for 2542_2543delG in ABCC6 and heterozygous for the deletion FH-Tonami-1.

We have found neither the nonsense variant p.R1141X nor the large deletion ABCC6del23-29 in our patients.

\section{Discussion}

$A B C C 6$ belongs to the ABC (ATP binding cassette) gene subfamily $\mathrm{C}$, which includes $A B C C 1-5, C F T R, A B C C 8$, and $A B C C 9$ (encoding the sulfonylurea receptor) (11). $A B C C 6$ consists of 31 exons spanning $\sim 75 \mathrm{~kb}$ of DNA and encodes a $165-\mathrm{kD}$ transmembrane protein. The ABCC6 protein is predicted to contain 17 membrane-spanning helices grouped into 3 transmembrane domains. Like other $\mathrm{ABC}$ transporters, the protein contains two intracellular nucleotide binding domains (NBD1 and NBD2). Each NBD has conserved Walker A and B motifs that are critical for ATPase function (11).

In the present study, two novel missense mutations, p.R1221C and p.R1357W, were found in a young female 
Novel Mutations in the ABCC6 Gene in Japanese PXE Patients

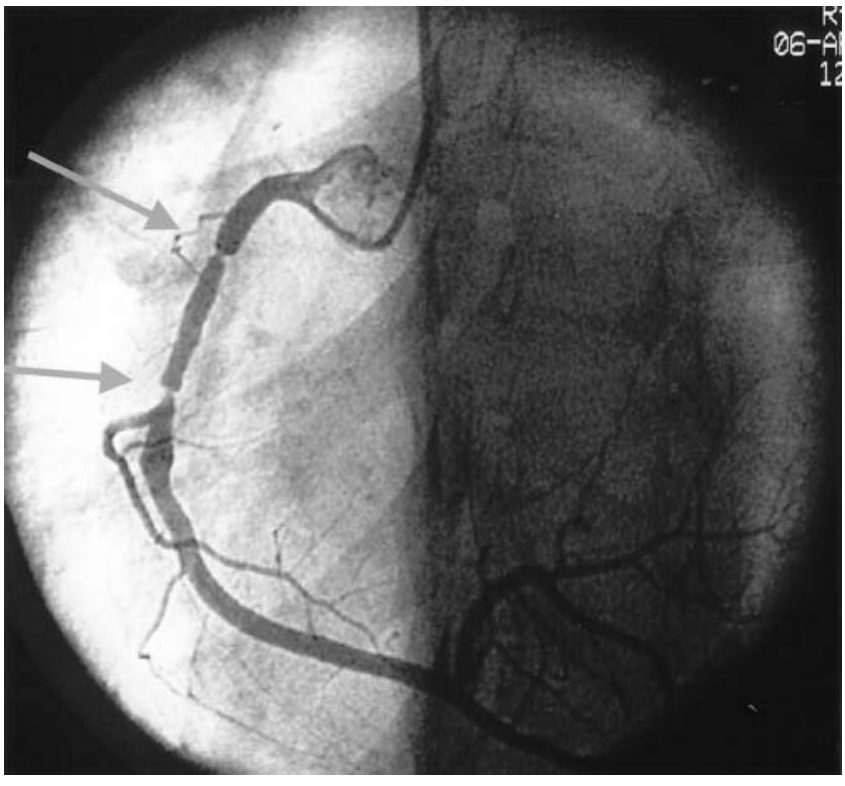

Right coronary artery

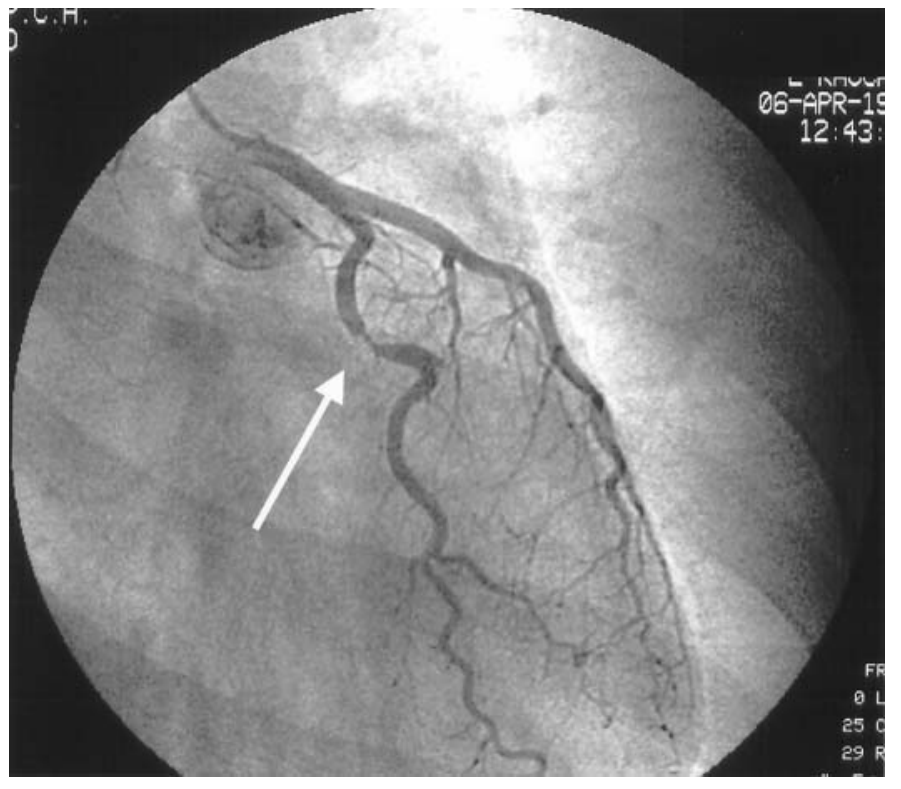

Left coronary artery

A

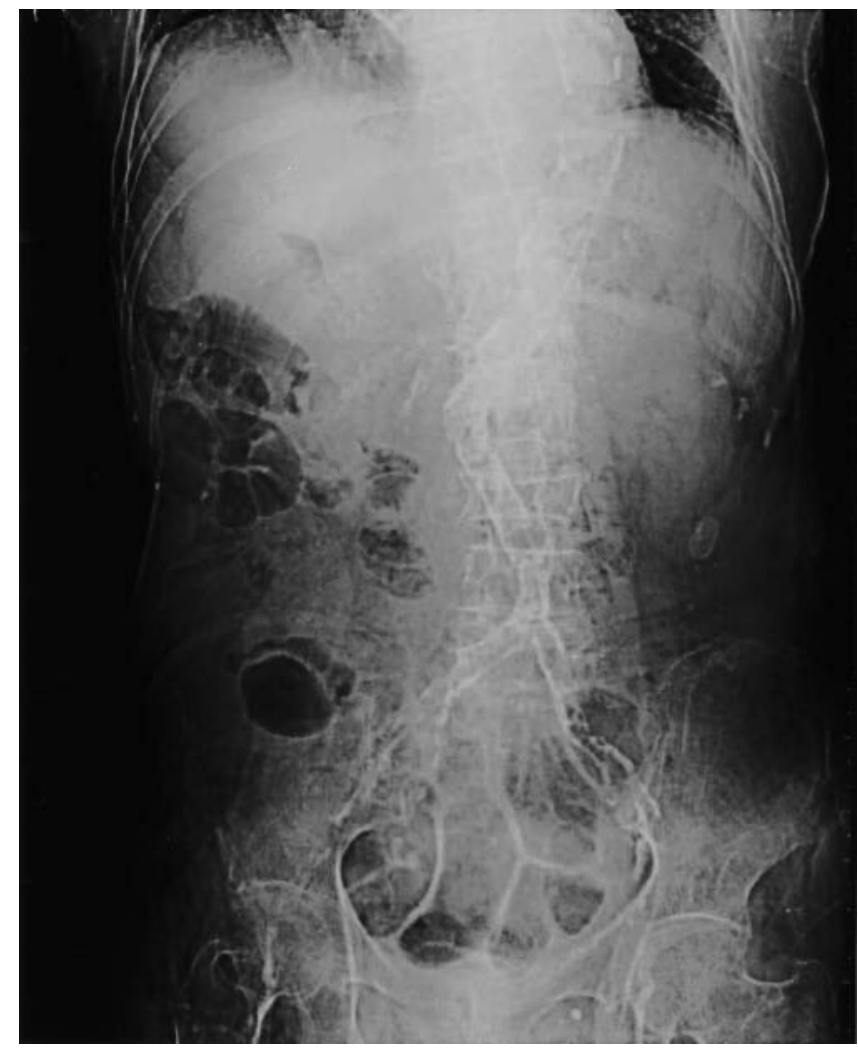

B
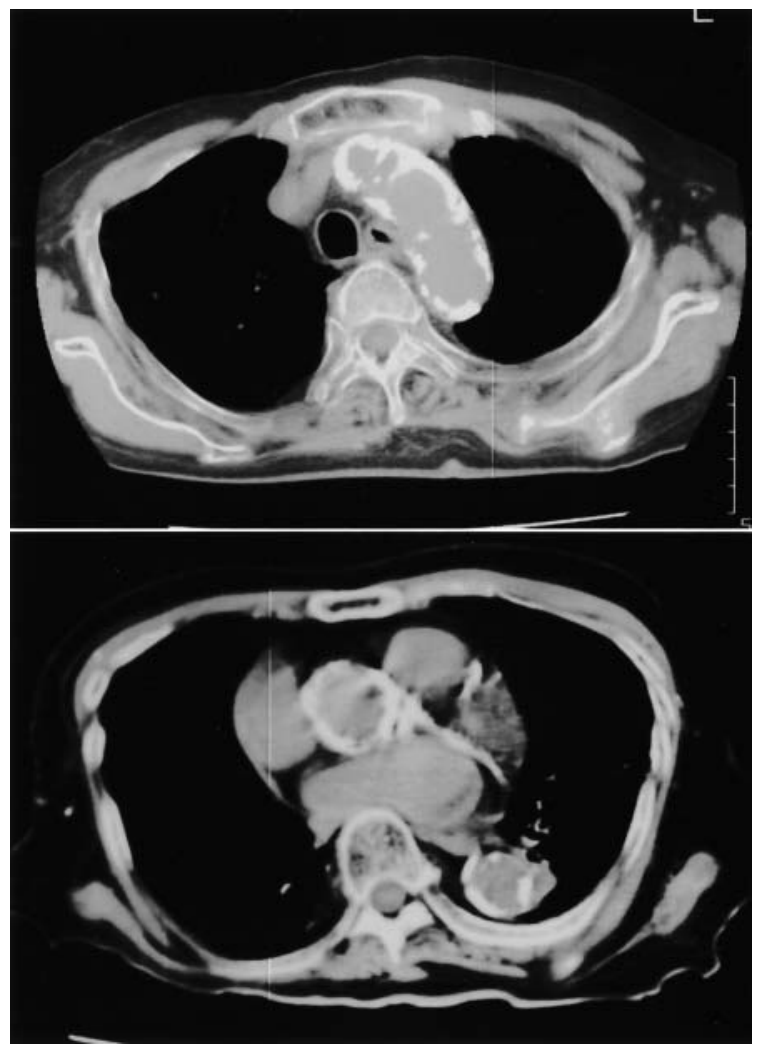

C

Figure 1. Phenotypic characteristics of PXE. A) Cardiac catheterization revealed that case 1 had severe stenosis (arrow) in both coronary arteries. B) X-ray image of case 2 showed that remarkable calcification was apparent from the ascending aorta to the femoral arteries. C) Severe calcification was revealed by computed tomography in the coronary arteries as well as aorta (case 2). 
Family 1

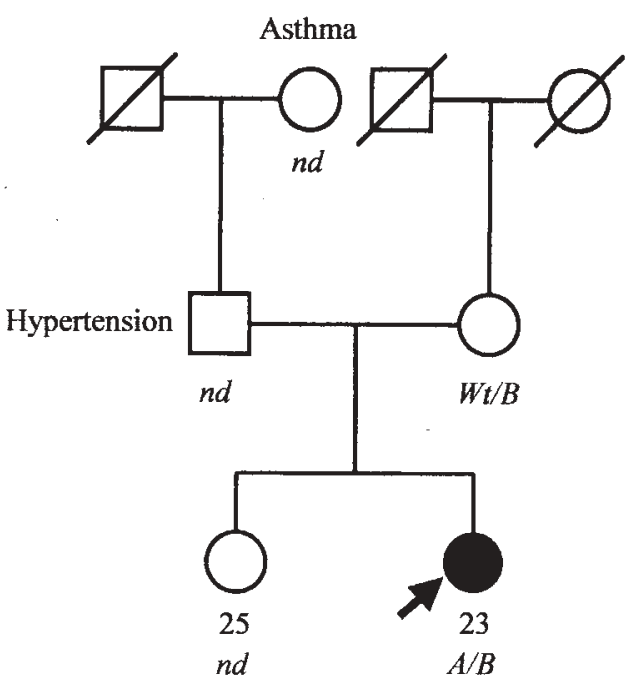

Family 2

(at proband's age of 53)

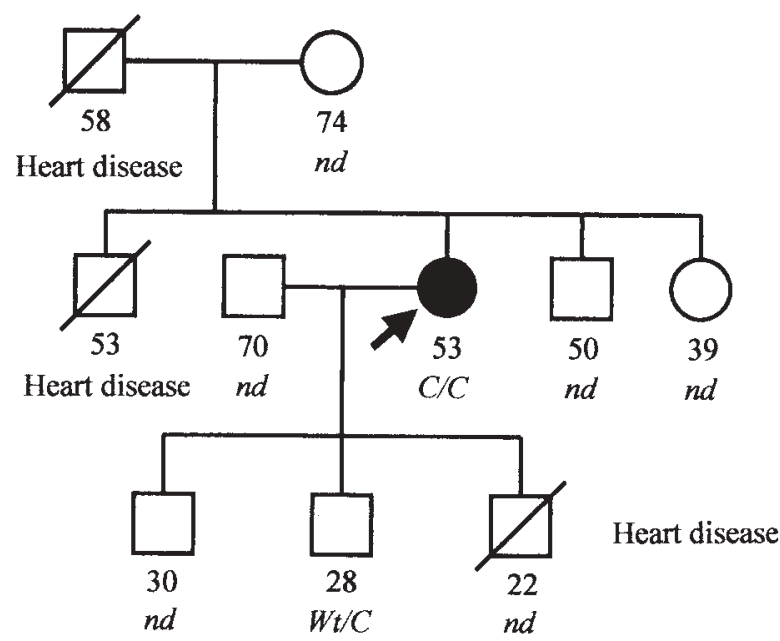

Figure 2. Pedigrees of two patients with PXE. (Family 1) In the family of the case 1, her mother was revealed to be heterozygous for p.R1357W. Her father has not been examined yet. (Family 2) The pedigree of case 2 at proband's age of 53. Her father, elder brother and the third son died of heart disease at 58, 53 and 22 years old, respectively. The proband and proband's second son showed hypercholesterolemia, although the other members did not.

patient who presented severe coronary stenosis. Arginines at positions 1221 and 1357 in the ABCC6 protein represent conserved residues among human $\mathrm{ABCC} 1$ (MRP1), ABCC2 (MRP2) and ABCC6 (MRP6) (4). The nonconservative amino acid substitutions found in case 1 were not detected in 100 clinically unaffected, unrelated control individuals. Therefore, we considered these two variants to be diseasecausing. p.R1221C and p.R1357W are novel disease-causing mutations in the ABCC6 gene that have not been previously reported.

p.R1221C is located between the 17th transmembrane helix and NBD2. p.R1357W was found in NBD2. In vitro transport studies with three PXE-causing mutants (p.V1298F, p.G1302R and p.G1321S) within NBD2, that had been expressed in Sf9 cells, showed markedly reduced transport activities (12). We would expect a similar effect for the p.R1357W. However, for other mutations such as p.R1221C, no such information is currently available.
A small deletion, 2542_2543delG is located C-terminally of NBD1. 2542_2543delG was predicted to result in premature termination of translation. Premature termination mutations frequently result in the nonsense-mediated decay of (NMD) of mutant mRNA products and significantly reduce mutant transcript levels (13). Therefore, the 2542_2543delG mutation could result in NMD.

The small deletion 2542_2543delG has previously been reported in only one case (14). The frequency of this deletion and the ethnicity of the patient(s) carrying this mutation were not reported.

PXE was first described as a sporadic disorder, but both autosomal recessive and autosomal dominant inheritances have been reported $(1,3,15)$. ABCC6 mutations have been reported in three families with apparently dominant PXE. In two families, the recurrent recessive mutation p.R1141X was identified in affected patients (3). In a third family, the three affected siblings were heterozygous for the maternal 
Novel Mutations in the ABCC6 Gene in Japanese PXE Patients

Table 1. Oligonucleotide Sequence

\begin{tabular}{|c|c|c|c|c|c|c|c|}
\hline Primer & Name & Sequence & $\begin{array}{l}\text { Product } \\
\text { size (bp) }\end{array}$ & Primer & Name & Sequence & $\begin{array}{l}\text { Product } \\
\text { size (bp) }\end{array}$ \\
\hline \multirow[t]{3}{*}{ Exon1 } & & & & Exon 18 & & & \\
\hline & E1F & 5'-GAATTTGGGGGTCTCTCCTC-3' & 191 & & E18F & 5'-AAGTGCTTCCTCTGCCTTTG-3' & 250 \\
\hline & E1R & 5'-GCCCAGAGACTTAGCGACAG-3' & & & E18R & 5'-CAGGCCACTGTTCCTTTTGT-3' & \\
\hline \multirow[t]{3}{*}{ Exon2 } & & & & Exon 19 & & & \\
\hline & $\mathrm{E} 2 \mathrm{~F}$ & 5'-CGAACATTGCCTGGTTCC-3' & 268 & & E19F & 5'-GAATCAGCAAAGCCCACCTA-3' & 269 \\
\hline & E2R & $5^{\prime}$-CCCTGCCTTGTACCATCCTA-3' & & & E19R & 5'-TGTTGGGATTACAGGCATGA-3' & \\
\hline \multirow[t]{3}{*}{ Exon3 } & & & & Exon 20 & & & \\
\hline & E3F & 5'-CTCCAGACTGAAGGCATCAT-3' & 207 & & E20F & 5'-AGCCTGTGCCCTTCTGAGT-3' & 200 \\
\hline & E3R & 5'-CCAGTTTGCTGTGACCTCTCT-3' & & & E20R & 5'-AGAGCGGTTAAGGCCACATA-3' & \\
\hline \multirow[t]{3}{*}{ Exon4 } & & & & Exon21 & & & \\
\hline & E4F & 5'-ATGAGCCACCATTTTGGTTT-3' & 206 & & $\mathrm{E} 21 \mathrm{~F}$ & 5'-ACATTTGGTGGGAGGACTTG-3' & 246 \\
\hline & E4R & 5'-CTAAGGGGCCTCCCTGACT-3' & & & E21R & 5'-CCCACCATTGGGAGAGATAC-3' & \\
\hline \multirow[t]{3}{*}{ Exon5 } & & & & Exon 22 & & & \\
\hline & $\mathrm{E} 5 \mathrm{~F}$ & 5'-GGAACAGGAATGAGGTTGGA-3' & 212 & & $\mathrm{E} 22 \mathrm{~F}$ & 5'-GATGAGGAGGGCAGGTGAG-3' & 256 \\
\hline & E5R & 5'-CTGAGCACCCTCCTCTGTCT-3' & & & E22R & 5'-CСТCTCCCTCATGTGTGCTA-3' & \\
\hline \multirow[t]{3}{*}{ Exon6 } & & & & Exon 23 & & & \\
\hline & E6F & 5'-GGGAATCAGAGCAGCAAATG-3' & 180 & & $\mathrm{E} 23 \mathrm{~F}$ & 5'-CCTCCCTGACCTCTCCGTA-3' & 368 \\
\hline & E6R & 5'-GTCTTCCTACCCTTGCCACA-3' & & & E23R & 5'-TCCAGCCCTCATGCTCTTAC-3' & \\
\hline \multirow[t]{3}{*}{ Exon7 } & & & & Exon24 & & & \\
\hline & E7F & 5'-TTCTTGACCTCCACCCACTT-3' & 241 & & $\mathrm{E} 24 \mathrm{~F}$ & 5'-CTGCCCTGGCTCTTCCTAC-3' & 251 \\
\hline & E7R & $5^{\prime}$-ACCCAGGGTCACACAGCTAC-3' & & & E24R & 5'-СТССТСТТСССТСТСССАТС-3' & \\
\hline \multirow[t]{3}{*}{ Exon8 } & & & & Exon 25 & & & \\
\hline & $\mathrm{E} 8 \mathrm{~F}$ & 5'-GAGACCACCCACCTTAGCAG-3' & 303 & & E25F & 5'-CCTCTGTCTGTCCCTCAAGC-3' & 205 \\
\hline & E8R & 5'-GCTGGCGGCTGAGAGTATAA-3' & & & E25R & 5'-TAACCACTCACCCTGCTGTC-3' & \\
\hline \multirow[t]{3}{*}{ Exon9 } & & & & Exon 26 & & & \\
\hline & E9F & 5'-CCCGCTCAGTGATACTGCTT-3' & 271 & & E26F & 5’-GATGTCAACAGGGACCCATT-3' & 200 \\
\hline & E9R & 5'-CAGCTGTACCTTCTCCСТCCT-3' & & & E26R & 5'-CCAGAGAGGCTTTCTTGCAC-3' & \\
\hline \multirow[t]{3}{*}{ Exon 10} & & & & Exon 27 & & & \\
\hline & $\mathrm{E} 10 \mathrm{~F}$ & 5'-ACTCCGTTCAAATCCCGTCT-3' & 239 & & $\mathrm{E} 27 \mathrm{~F}$ & 5'-GTCCTTTGGCCTAAACTCCA-3' & 221 \\
\hline & E10R & 5'-GGCCTCCCCACTTTACTTCT-3' & & & E27R & 5'-ACTCAGTTTCCCCTCCTGCT-3' & \\
\hline \multirow[t]{3}{*}{ Exon11 } & & & & Exon 28 & & & \\
\hline & $\mathrm{E} 11 \mathrm{~F}$ & 5'-GTGGCTTCCTCCCTACTTCC-3' & 200 & & $\mathrm{E} 28 \mathrm{~F}$ & 5'-ACCATGCCTCCCATCTTTG-3' & 260 \\
\hline & E11R & 5'-CTCTGAGAGCTGGGCTCCT-3' & & & E28R & $5^{\prime}$-CCAATAAATGCCCACAAACC-3' & \\
\hline \multirow[t]{3}{*}{ Exon12 } & & & & Exon29 & & & \\
\hline & $\mathrm{E} 12 \mathrm{~F}$ & 5'-CAGTGCTGCTCAGCATAGAGA-3' & 306 & & E29F & 5'-ATTTCCTGAAGGCCCTTGG-3' & 303 \\
\hline & E12R & 5'-GTCAGGGTGCAGGGAAGAAT-3' & & & E29R & 5'-AAAGATGGGAGGCATGGTG-3' & \\
\hline \multirow[t]{3}{*}{ Exon 13} & & & & Exon 30 & & & \\
\hline & $\mathrm{E} 13 \mathrm{~F}$ & 5'-GAAGCTGGAGCCAGGTGTAG-3' & 263 & & E30F & 5'-GGCTGCTGTGAGGTCAGG-3' & 258 \\
\hline & E13R & 5'-TATCCATGCTTGCGTGTCTC-3' & & & E30R & 5'-CCAGCTAATTGTCCCAATCG-3' & \\
\hline \multirow[t]{3}{*}{ Exon 14} & & & & Exon $31 \alpha^{*}$ & & & \\
\hline & E14F & 5'-CAGTACTGATGCTGGCTTGC-3' & 217 & & $\mathrm{E} 31 \mathrm{~F} \alpha$ & 5'-TGGGGTACCAAGTACACGAA-3' & 360 \\
\hline & E14R & 5'-CTCTTCTTGCTGGGTGACCT-3' & & & $\mathrm{E} 31 \mathrm{R} \alpha$ & 5'-AGACCTGTGTTTGCTCTCTGG-3' & \\
\hline \multirow[t]{3}{*}{ Exon 15} & & & & Exon $31 \beta^{*}$ & & & \\
\hline & $\mathrm{E} 15 \mathrm{~F}$ & 5'-GGCTGGTTACTACGGGTGTC-3' & 142 & & $\mathrm{E} 31 \mathrm{~F} \beta$ & 5'-GCCACTTTCTCTGCCATTTT-3' & 286 \\
\hline & E15R & 5'-CAGGGGTCTCCTGTAAATGG-3' & & & $\mathrm{E} 31 \mathrm{R} \beta$ & 5'-GCCTCTCTGTCTCCCTCTCC-3' & \\
\hline \multirow[t]{3}{*}{ Exon 16} & & & & ABCC6del23-29 & & & \\
\hline & $\mathrm{E} 16 \mathrm{~F}$ & 5'-GATGGGGACATCCTAGCAGA-3' & 198 & & DEL-1 & 5'-GGAATACTCAAGGCGAATGG-3' & 652 \\
\hline & E16R & 5'-CAAGGTCATGTCTCCCCTCT-3' & & & DEL-2 & 5'-TCTTGAAGCAGCAGTGAGTC-3' & 552 \\
\hline \multirow[t]{3}{*}{ Exon 17} & & & & & DEL-3 & 5'-TTGAGCAGGCTGACTGTAGG-3' & \\
\hline & $\mathrm{E} 17 \mathrm{~F}$ & $5^{\prime}$-TGTCTCCCTGTCCCAAAAAG-3' & 250 & & & & \\
\hline & E17R & 5'-CATCATCCTCCTGTGACCAA-3' & & & & & \\
\hline
\end{tabular}

*Exon $31 \alpha$ primer set can amplify the first half of exon 31 , and Exon $31 \beta$ primer set can amplify the latter half.

inherited p.R1495C mutation. Autosomal recessive inheritance could not be excluded in this family, however, as the three patients inherited the same paternal allele (16). In fact, no molecular evidence for autosomal dominant inheritance has been demonstrated at present, although some of the heterozygous carriers may demonstrate minimal manifestation of the disease (17). Taken together, these data support a unique recessive mode of inheritance in PXE (18).
Ohtani and Furukawa reported a very preliminary mutational analysis of a Japanese patient (6). They examined only 5 out of the 31 exons of $A B C C 6$ and failed to find any mutation responsible for PXE. They did not examine the exons in which we identified as disease-causing mutations in our patients that include exon 19 [2542_2543delG], exon 26 [p.R1221C], and exon 29 [p.R1357W].

In summary, we have performed mutational analysis for 
all 31 exons of ABCC6 gene in Japanese patients with PXE. Two novel mutations, both affecting highly conserved amino acids and one previously reported mutation responsible for PXE have been identified. To the best of our knowledge, this is the first report of mutation identification in the ABCC6 gene in Japanese PXE patients in the English language literature. However, one of the major limitations of this study is that only restricted family members were analyzed. Because the number of patients in this study was small, further investigations for a nation-wide survey of Japanese patients with PXE are needed to determine, if indeed a different spectrum of private and recurrent mutations in ABCC6 is responsible for PXE in the Japanese population as compared to the previously studied North American and European populations.

Acknowledgements: We express special thanks to Yoshiaki Kazama for his effort to collect patient information. Sachio Yamamoto, Mihoko Mizuno and Saeko Takezawa are also thanked for their excellent technical assistance.

\section{References}

1) Neldner KH. Pseudoxanthoma elasticum. Clin Dermatol 6: 1-159, 1988.

2) Le Saux O, Urban Z, Tschuch C, et al. Mutations in a gene encoding an $\mathrm{ABC}$ transporter cause pseudoxanthoma elasticum. Nat Genet $\mathbf{2 5}$ : 223-227, 2000

3) Bergen AA, Plomp AS, Schuurman EJ, et al. Mutations in ABCC6 cause pseudoxanthoma elasticum. Nat Genet 25: 228-231, 2000.

4) Kool M, van der Linden M, Haas M, Baas F, Borst P. Expression of human MRP6, a homologue of the multidrug resistance protein gene MRP1, in tissues and cancer cells. Cancer Res 59: 175-182, 1999.

5) Le Saux O, Beck K, Sachsinger C, et al. A spectrum of ABCC6 mutations is responsible for pseudoxanthoma elasticum. Am J Hum Genet
69: 749-764, 2001 (Erratum in: Am J Hum Genet 69: 1413, 2001. Am J Hum Genet 71: 448, 2002.).

6) Ohtani T, Furukawa F. Pseudoxanthoma elasticum: Report of a case without any mutations in 5 exons of the MRP6 gene. J Dermatol 29: 46-47, 2002.

7) Magosaki N, Seo M, Kyoi Y, et al. A case of pseudoxanthoma elasticum associated with familial hypercholesterolemia. Nippon Naika Gakkai Zasshi 70: 417-422, 1981 (in Japanese).

8) Orita M, Iwahana H, Kanazawa H, Hayashi K, Sekiya T. Detection of polymorphisms of human DNA by gel electrophoresis as single-strand conformation polymorphisms. Proc Natl Acad Sci USA 86: 27662770, 1989.

9) Ringpfeil F, Nakano A, Uitto J, Pulkkinen L. Compound heterozygosity for a recurrent $16.5-\mathrm{kb}$ Alu-mediated deletion mutation and single-base-pair substitutions in the ABCC6 gene results in pseudoxanthoma elasticum. Am J Hum Genet 68: 642-652, 2001.

10) Kajinami $\mathrm{K}$, Mabuchi $\mathrm{H}$, Ito $\mathrm{H}$, et al. New variant of low density lipoprotein receptor gene, FH Tonami. Arteriosclerosis 8: 187-192, 1988.

11) Borst P, Evers R, Kool M, Wijnholds J. The multidrug resistance protein family. Biochim Biophys Acta 1461: 347-357, 1999.

12) Ilias A, Urban Z, Seidl TL, et al. Loss of ATP-dependent transport activity in pseudoxanthoma elasticum-associated mutans of human ABCC6 (MRP6). J Biol Chem 277: 16860-16867, 2002.

13) Frischmeyer PA, Dietz HC. Nonsense-mediated mRNA decay in health and disease. Hum Mol Genet 8: 1893-1900, 1999.

14) Uitto J, Pulkkinen L, Ringpfeil F. Molecular genetics of pseudoxanthoma elasticum: A metabolic disorder at the environment-genome interface? Trends Mol Med 7: 13-17, 2001.

15) Pope FM. Historical evidence for the genetic heterogeneity of pseudoxanthoma elasticum. Br J Dermatol 92: 493-509, 1975.

16) Hu X, Plomp A, Wijnholds J, Ten Brink J, et al. ABCC6/MRP6 mutations: further insight into the molecular pathology of pseudoxanthoma elasticum. Eur J Hum Genet 11: 215-224, 2003.

17) Sherer DW, Bercovitch L, Lebwohl M. Pseudoxanthoma elasticum: significance of limited phenotypic expression in parents of affected offspring. J Am Acad Dermatol 44: 534-537, 2001.

18) Chassaing N, Martin L, Mazereeuw J, et al. Novel ABCC6 mutations in pseudoxanthoma elasticum. J Invest Dermatol 122: 608-613, 2004. 